\title{
Artigo \\ No princípio era a terra: \\ A territorialização das lutas agrárias \\ no contexto de expansão da \\ acumulação capitalista na Amazônia
}

\author{
Wendell Ficher Assis \\ Universidade Federal de Alagoas
}

RESUMO: O trabalho procura analisar as complementaridades e dissonâncias entre as lutas camponesas por terra, mais associadas à reforma agrária e aos mecanismos de redistribuição, e os embates protagonizados por indígenas, quilombolas e populações tradicionais, que lutam pela manutenção e conquista de territórios, ao mesmo tempo em que demandam do Estado o reconhecimento de seus modos específicos de ser, viver e produzir. Para tanto, empreendeu-se a realização de trabalhos de campo na região Oeste do Pará, que desde a última década tem sido locus de intensos conflitos fundiários envolvendo as novas frentes de acumulação capitalista e as populações tradicionais e camponesas. Poder-se-ia sugerir de forma preliminar que uma demanda por terra não desafia, necessariamente, as regulações com que se administra o direito à propriedade, ao passo que uma demanda territorial evoca questões de poder, de afirmação de identidade, de autogestão e controle dos recursos naturais, procurando impor uma nova territorialização.

PALAVRAS-CHAVE: Conflitos agrários, territorialização das lutas, Amazônia. 
No meu entendimento, o nativo daqui da Amazônia não tinha preocupação com território, porque a gente se criou desde os nossos antepassados que isso aqui tudo era nosso e não tinha preocupação. Eu me lembro em Belterra meu pai trabalhava para a companhia Ford, mas para interar o salário depois do seringal, permitiu que se fizesse um roçado. Aí mamãe, papai faziam um roçado de duas tarefas, meio hectare de terra, esse ano, ali eles plantavam o arroz, plantavam o feijão, plantavam o milho, a banana, depois de dois anos o meu pai saía dali e ia para outro local, aí chegava um outro para fazer o plantio ali, mas não ia lá perguntar para o papai, porque aquilo ali era, aquilo era da companhia, era assim que se dizia. Com a chegada das novas frentes como tu chamastes, aí começou a ver os mecanismos de defesa do território, vamos segurar porque esses caras estão invadindo tudo. (Entrevista com liderança religiosa do Baixo Amazonas, Santarém, 04/06/2012).

\section{Introdução}

Esse trabalho pretende demonstrar que a constituição e perpetuação de um mercado de terras pouco regulado jurídica e socialmente contribuiu e segue contribuindo para a manutenção de formas de produção econômica que expropriam populações tradicionais e camponesas, facilitando a continuidade e prevalência de uma exploração capitalista dos recursos naturais fundada, não raro, na apropriação violenta de imensos espaços geográficos. A questão agrária representa historicamente um problema nodal no Brasil e pode-se indicar que sua interpretação desembocou na formulação de duas abordagens teóricas que têm sido objeto de esforços levados a cabo por distintos pesquisadores do campo das ciências sociais: de um lado, os que articulam a problemática das demandas por terra "de trabalho" por parte de grupos camponeses fundados na tradição do trabalho familiar e, de outro, os que salientam a existência de demandas por territórios identitários vistos como espaços particulares dotados de peculiaridades associadas aos seus modos de uso material e simbólico (Acselrad, 2012).

Com o objetivo de compreender as aproximações e distanciamentos, fraturas e complementaridades entre essas duas abordagens, bem como tentar desvendar se e em que medida essas diferentes formulações teóricas rebatem no campo de luta prática dos movimentos sociais, empreendeu-se a realização de dois trabalhos de campo conduzidos na região Oeste do Pará, que desde a última década tem sido locus de intensos conflitos fundiários envolvendo as novas frentes de acumulação capitalista (madeireiros ilegais e com concessão florestal, agronegócio sojicultor, pecuária e mineração) e as populações tradicionais (ribeirinhos, extrativistas), indígenas, quilombolas e populações camponesas. Assim sendo, o primeiro trabalho de campo foi desenvolvido entre os dias 12/09 e 
05/10/2009 no âmbito do projeto de pesquisa "Experiências em cartografia social e constituição de sujeitos em conflitos ambientais", cujo intuito foi compreender como estava se dando a destinação de terras no conjunto de glebas Mamurú-Arapiuns ${ }^{1}$, bem como analisar as formas de atuação das populações tradicionais e movimentos sociais na construção de uma proposta contra-hegemônica de uso e apropriação dos territórios (Assis, 2010).

O segundo trabalho transcorreu entre os dias 21/05 e 14/07/2012 e se desenrolou em duas fases. Em um primeiro momento foram realizadas entrevistas em Belém com representantes do Instituto de Terras do Estado do Pará - Iterpa, com lideranças do Conselho Nacional dos Seringueiros - CNS e com membros da Coordenação das Associações das Comunidades Remanescentes de Quilombos do Pará - Malungu. Já a segunda fase privilegiou a realização de entrevistas com lideranças comunitárias, líderes sindicais, representantes de movimentos sociais e de organizações não governamentais, das zonas rurais e urbanas dos municípios de Santarém, ${ }^{2}$ Juruti, Óbidos e Belterra.

Com base no material coletado, espera-se traçar um esboço capaz de iluminar a relação entre as lutas camponesas por terra, mais associadas à reforma agrária e aos mecanismos de redistribuição, e os embates protagonizados por indígenas, quilombolas e populações tradicionais, que lutam pela manutenção e conquista de territórios, ao mesmo tempo em que demandam do Estado o reconhecimento de seus modos específicos de ser, viver e produzir. Poder-se-ia sugerir de forma preliminar que uma demanda por terra não desafia, necessariamente, as regras e regulações com que se administra o direito à propriedade, ao passo que uma demanda territorial evoca questões de poder, de afirmação de identidade, de autogestão e controle dos recursos naturais, procurando impor uma nova territorialização que, no interior do espaço nacional, é fundamentada na cidadania territorial (Offen, 2009). Não obstante, há que considerar se, e em que medida, as lutas por reconhecimento territorial têm logrado conter ou rivalizar com as frentes de expansão econômica e de integração de novas terras nos circuitos de acumulação do capital.

\section{Os caminhos da metamorfose: As fronteiras entre terra e território}

A partir dos anos 1960, consolida-se uma ruptura na relação de complementariedade, até então existente, entre latifúndio e agricultura camponesa. Os investimentos de novos capitais e a consolidação de explorações agropecuárias mercantis intensificaram a ocupação 
do território desencadeando uma movimentação, sobretudo na Amazônia, que encetou novas formas de apropriação das terras. Para Ianni (1979a), as relações econômicas e políticas dos homens, historicamente, produzem alterações nos significados sociais atribuídos à terra, constituindo-a como um tipo de relação social. Assim, a penetração do capitalismo no meio rural engendra novos significados e formas sociais, imprimindo uma repentina metamorfose no regime fundiário nacional. A terra que parecia larga, farta e sem fim, de súbito ganha outra fisionomia social; o solo que antes parecia um elemento secundário e mesmo irrelevante, uma vez que o princípio de exploração se baseava na abundância de terras com escassez de capitais, passa a desempenhar um papel econômico e sociopolítico central.

Ianni (1979a) sinaliza para um contínuo processo de mercantilização das terras que alimenta um rearranjo jurídico na estrutura fundiária, bem como propicia a incorporação de novos espaços nos circuitos de acumulação do capital. Nesse sentido, para manutenção da posse das terras passa a ser necessário revestir-se de um título de propriedade, que seja legalmente reconhecido e afiance a permanência. Não obstante, Caio Prado Junior (1979) afirma que desde o início da ocupação e colonização do território brasileiro os títulos de propriedade e o domínio das terras galoparam muito adiante da frente pioneira de penetração e ocupação. Assim, sinaliza para a fragilidade desse arranjo jurídico ao destacar, em sua contribuição à análise da questão agrária, que:

Naquelas regiões desertas o direito de propriedade necessita materializar-se de alguma forma tangível a fim que se perceba a sua existência [...]. Não basta assim a um tal direito de propriedade a simples transcrição no registro de imóveis de vagas referências e descrições baseadas em incertos acidentes geográficos e abstratos rumos e configurações geométricas. A propriedade da terra fundada em bases tão precárias e sutilezas jurídicas irreais não deve e não pode servir de obstáculo à efetiva utilização e valorização por aqueles que as pretendem e delas necessitam para instalarem seu lar e assegurarem assim a subsistência própria e de suas famílias (Prado Junior, 1979: 123).

Diferentemente dos Estados Unidos onde a disponibilidade de terras na fronteira agrícola funcionou como alicerce da democracia, ao mesmo tempo em que possibilitou o assentamento de colonos (Turner, 1963), no Brasil a lei de terras de 1850 instituiu a compra como modalidade de acesso à terra, privilegiando a capacidade monetária e impossibilitando a ocupação primeiramente dos escravos libertos e posteriormente dos colonos migrantes. A mercantilização da terra é, assim, um claro artifício produzido pela própria expansão capitalista (Martins, 1986). Pode-se dizer que no Brasil as terras de 
fronteira foram e continuam sendo incorporadas sob os auspícios de uma dinâmica que privilegia a produção capitalista no campo, sendo essa alicerçada em incentivos e políticas de Estado que estimulam a continuidade da grande exploração territorial. ${ }^{3}$ Do ponto de vista do empreendimento capitalista, "a existência de terras sem dono na fronteira" funcionou e funciona como um regulador da intensificação das atividades agropecuárias, condicionando o ritmo de exploração, bem como a opção por regimes de produção territorialmente mais intensivos ou extensivos (Silva, 1981). Isso deriva do fato de que, nas terras de fronteira, as frentes econômicas podem contar tanto com a ilegalidade da grilagem violenta quanto com aquisições a baixo custo, com documentação açodada e incentivos fiscais. A esse respeito, Ianni (1979b) assinala que no Brasil a incorporação de novas terras

[f]oi e continua a ser o contexto econômico e político no qual se dá o rearranjo jurídico da estrutura fundiária [....]. Ocorre a monopolização das terras pelos proprietários dos meios de produção do capital nacional ou estrangeiro. A terra é transformada em mercadoria, objeto e meio da produção de valores de troca, e é colocada no circuito da reprodução do capital, como propriedade privada (Ianni, 1979b: 158).

Sobre esse aspecto, José Graziano Silva (1981) destaca que o fechamento da fronteira e a indisponibilidade de terras no Brasil se processam não por uma ocupação no sentido clássico de expansão de áreas cultivadas a partir das regiões mais antigas, onde a produção capitalista substituiu a produção de subsistência dos antigos posseiros, deslocando-os para novas áreas. Aqui teria ocorrido, pelo contrário, um fechamento de fora para dentro, onde a terra perde seu papel produtivo e assume apenas o de reserva de valor especulativo. Não é a ocupação efetiva do solo por parte dos colonos, mas sim uma exploração pela pecuária extensiva com a finalidade precípua de garantir a propriedade da terra. A isso, agrega-se o fato desse fenômeno ter sido, em grande medida, favorecido por iniciativas governamentais que incitaram e financiaram a ocupação das terras de fronteira por grandes empresas agropecuárias beneficiárias de incentivos fiscais. Da ótica de Little (2001), na Amazônia as fronteiras não têm sido somente abertas ou fechadas, mas são constantemente reabertas para no momento seguinte se fecharem; assim, a existência de fronteiras na região amazônica vem sendo um fenômeno perene estimulado pela constante chegada de novos grupos sociais que buscam se apropriar dos recursos naturais, desencadeando processos de desterritorialização e reterritorialização baseados em diferentes modos de apropriação do espaço. 
No tocante à temática da fronteira, Guedes (2011), retomando o debate dos anos 1970 e 1980 entre José de Souza Martins e Otávio Guilherme Velho, procurar salientar a fecundidade de tal "objeto" e/ou "ponto de vista", para ajudar a pensar as relações e tensões entre as formas de reivindicação relacionadas às lutas por terra e aquelas direcionadas à demanda por territórios, uma vez que estão em jogo não apenas mudanças "objetivas" no escopo propriamente dito dessas demandas, mas também nas formas através das quais elas (e aqueles e aquilo a elas associadas) são formuladas, explicitadas e representadas pelos cientistas sociais, cujo papel não pode ser deixado em segundo plano. Não cabe aqui esmiuçar esse frutífero diálogo já apresentado por Guedes (2011), mas interessa reter que, para Martins (1980), há diferenciações entre as frentes de expansão que são resultado do avanço da ocupação por parte de posseiros, que, por sua vez, são deslocados pelas frentes pioneiras expressas pelas formas empresariais e capitalistas de ocupação do território. Nesse sentido, as noções de frente de expansão e frente pioneira levam a ver diferentes coisas, porque são expressões distintas da mesma coisa, qual seja, o deslocamento da lógica do capital em direção a novos territórios (Martins, 1996).

De acordo com Martins (1998), no cenário conflituoso da fronteira, camponeses de mentalidade tradicional são alcançados pela expansão da propriedade privada e por meio dela pela expansão da empresa capitalista moderna; haveria, assim, um choque e um conflito irremediável entre duas lógicas: a do camponês, fundada no trabalho na terra, e a do capitalista, alicerçada na exploração mercantil, que transforma a terra em propriedade privada. Esse é o foco principal das críticas de Velho (1981), que argumenta que, ao contrário da existência de uma contraposição rígida ou de um embate entre diferentes lógicas, ocorreria sim uma subordinação do campesinato da fronteira a um capital mercantil e usurário que já o acompanharia antes mesmo de ele ocupar aquelas áreas, sendo por vezes até mesmo responsável pelo seu deslocamento para lá (Guedes, 2011). Diferentemente de ambos, Little (2001) argumenta que a história da fronteira na Amazônia não é um processo de sucessão linear; ao contrário, resulta da coexistência de temporalidades, da interpenetração cultural e da recorrência de disputas territoriais.

Esse debate ilumina um processo hodierno que vem se desenrolando na destinação de terras públicas do conjunto de glebas Mamurú-Arapiuns no Oeste do Pará, mais especificamente, na Gleba Nova Olinda I. Lá se pôde observar durante o trabalho de campo que uma mesma frente pioneira (para usar a terminologia de Martins) desencadeia, de um lado, a ocorrência de conflitos, e, de outro, favorece o afloramento ou a perpetuação de relações de patronagem. Como se verá no transcorrer do presente artigo, não há espaço 
exclusivo nem para o dualismo de lógicas distintas, gerador do conflito (Martins), nem tampouco para a subordinação e vinculação integrada às relações capitalistas (Velho); essas formas se combinam, se alternam e se opõem, em virtude da chegada de novas frentes e da relação que logram estabelecer com as comunidades.

Longe de uma configuração de homogeneidade-sincrônica, as populações da Gleba Nova Olinda I apresentam formas diferenciadas de organização social, política e cultural que são reflexo do histórico trilhado por cada comunidade. Nesse contexto, as disputas internas e externas, o faccicionismo e a diferenciação econômica rompem com a visão idílica de unidade comunitária e homogeneidade social (Almeida, 1988). Essas comunidades, ao modo das sociedades tidas como complexas, estão inseridas em processos históricos que têm consequências nas microrrelações, bem como efeitos nas escalas mais amplas do modo de produção capitalista. Assim, na esfera mais localizada das comunidades, engendram-se contradições que espelham dicotomias do mundo modernocolonial (Wallerstein, 1974), tais como desenvolvido/arcaico, moderno/tradicional, veloz/lento, civilizado/bárbaro, integrado/isolado. A expansão da fronteira na Amazônia está, assim, vinculada às forças do colonialismo, imperialismo e do capitalismo mercantil, processos esses que continuamente impulsionam a chegada de novos grupos sociais com vistas à exploração dos recursos naturais (Little, 2001). Essas comunidades ribeirinhas não estão, portanto, afastadas dos grandes circuitos de acumulação do capital, ao contrário, são alicerces para manutenção e avanço de uma lógica mercantil que continuamente coloniza novos espaços.

Uma das facetas da heterogeneidade dessas relações sociais pode ser apreendida ao se analisar os vínculos entre as comunidades, madeireiros e grileiros, bem como quando se inferem os impactos dessas interações sobre as formas de titulação das terras. A esse respeito, algumas pistas podem ser extraídas do quadro disposto a seguir, que sintetiza as opções das comunidades da Gleba Nova Olinda I no que se refere às modalidades de titulação:

\begin{tabular}{|l|l|l|l|l|l|}
\hline $\begin{array}{l}\text { Rio } \\
\text { Maró }\end{array}$ & Comunidade & $\begin{array}{l}\text { Distância barco motor } \\
\text { Santarém }(\mathrm{h})\end{array}$ & $\begin{array}{l}\text { Número de } \\
\text { Famílias }\end{array}$ & $\begin{array}{l}\text { Área por } \\
\text { Família (ha) }\end{array}$ & $\begin{array}{l}\text { Tipo de Regularização } \\
\text { Fundiária }\end{array}$ \\
\hline \multirow{7}{*}{} & Mariazinha & 46 & 24 & 100,00 & Individual \\
\cline { 2 - 6 } & Repartimento & 39 & 30 & 100,00 & Individual \\
\cline { 2 - 6 } & Fé em Deus & 15 & 41 & 100,00 & Individual \\
\cline { 2 - 6 } & Vista Alegre & 30 & 21 & 148,48 & Coletiva \\
\cline { 2 - 6 } & Prainha & 14 & 12 & 216,73 & Coletiva \\
\cline { 2 - 6 } & Novo Lugar* & 13 & 18 & 629,54 & Coletiva \\
\cline { 2 - 6 } & $\begin{array}{l}\text { Cachoeira do* } \\
\text { Maró }\end{array}$ & 12 & 18 & 629,54 & Coletiva \\
\cline { 2 - 5 } & São José III* & 12 & 11 & 629,54 & Coletiva \\
\hline
\end{tabular}




\begin{tabular}{|l|l|l|l|l|l|}
\hline $\begin{array}{l}\text { Rio } \\
\text { Aruã }\end{array}$ & $\begin{array}{l}\text { Sociedade dos } \\
\text { Parentes }\end{array}$ & 12 & 26 & 100,00 & Individual \\
\hline \multirow{7}{*}{} & Sempre Serve & 12 & 29 & 100,00 & Individual \\
\cline { 2 - 6 } & São Luiz** & 12 & 13 & 306,05 & Coletiva \\
\cline { 2 - 6 } & Novo Paraíso** & 13 & 16 & 306,05 & Coletiva \\
\cline { 2 - 6 } & São Francisco** & 17 & 34 & 306,05 & Coletiva \\
\cline { 2 - 6 } & São Raimundo** & 17 & 25 & 306,05 & Coletiva \\
\hline
\end{tabular}

* Comunidades que se autorreconheceram como indígenas e demandam da Funai a demarcação da Terra Indígena Maró.

** Comunidades tituladas através do decreto 1.738 de 17/06/2009, que instituiu uma área de 23.632 hectares e consolidou o PEAX Aruã.

Fonte: Ideflor, 2009.

A rigor, todas essas comunidades poderiam ser qualificadas na terminologia atual como populações tradicionais, no entanto, nem todas acionam o pertencimento ao território e a afirmação de identidades diferenciais como forma de garantir a permanência no lugar; pelo contrário, algumas expressam sua preferência por uma regularização fundiária individual, com parcelamento dos lotes e com cláusula de inalienabilidade de no máximo 10 anos, características que as aproximariam da lógica do mercado e das demandas por terras de trabalho. Aqui se podem estabelecer relações entre o debate Martins/Velho e o processo de titulação e destinação das terras na Gleba Nova Olinda I. Nas comunidades onde as frentes de acumulação expressas na figura de madeireiros e grileiros lograram estabelecer relações mais orientadas por uma subordinação ao capital, por via da patronagem, a escolha por parte dos ribeirinhos foi pela titulação individual, que, em última instância, facilita a incorporação e reconcentração de terras por parte dos grupos empresariais. Já nas comunidades que acionaram características de pertencimento ao território e de afirmação identitária, inclusive com autorreconhecimento indígena, há um conflito forte em relação à presença dos madeireiros e grileiros, que desemboca na demanda de constituição de territórios coletivos e terras indígenas.

Assim, no contexto de expansão de novas frentes de acumulação, pode-se verificar tanto a incorporação de novas terras nos circuitos de acumulação de capital quanto a ocorrência de uma politização da ocupação, que demanda do Estado o reconhecimento de direitos territoriais específicos, tendo como decorrência a retirada das terras do mercado fundiário. Nesse sentido, o que era visto como terra de uso comum pode politicamente se transformar em um território, ao passo que o que era visto como território indivisível e de todos pode ser recortado para dar lugar a porções de terra paulatinamente inseridas no mercado. A opção por titulação individual das comunidades ribeirinhas que mantêm relações de emprego e patronagem com madeireiros e grileiros acaba por inseri-las num 
enquadramento mais próximo às demandas por terra de trabalho, mais associadas à luta camponesa, reconfigurando sua relação com o território e com as comunidades vizinhas, uma vez que a demarcação de lotes as insere em uma nova lógica - o território de uso irrestrito e sem cercas é agora retalhado e transformado em terra de trabalho restrita a 100 hectares, que, inclusive, pode ser comercializada. Há por essa via a emergência de conflitos entre as comunidades e isso pôde ser verificado durante a realização dos dois trabalhos de campo, como se pode notar nos fragmentos transcritos a seguir:

Esse é meu irmão, esse sobrinho, aquele neto, essa sobrinha, aquela irmã, ali sobrinho, sobrinha, neto, filha, irmão [aponta as pessoas presentes no recinto]. Aqui somos todos parentes, abaixo de Deus é essa minha irmã e eu que somos os mais velhos. Então qual é a nossa? Já andamos na luta, fui a Belém e Santarém na defesa de nosso território. A gente vê que a discussão aqui no Maró está cheia de traição dos próprios vizinhos. (...) Nós bebíamos tarobá [bebida típica dos ribeirinhos] com essas comunidades vizinhas e agora está tudo envenenado, não se tem união é pura inimizade (Entrevista com liderança F. Aldeia Novo Lugar - Rio Maró, Santarém/PA, 29/09/2009).

Hoje nós enfrentamos um problema sério na Resex Tapajós. Agora há pouco eu tive uma reunião com o Icmbio e com a coordenação da Tapajoara, porque o Governo do Estado do Pará através do Iterpa subdividiu a gleba Nova Olinda I para ter assentamento individual e assentamento coletivo e ao mesmo tempo induziu essas lideranças a se trocarem por pequenos presentes. Hoje você vai ao Assentamento Fé em Deus, que foi um assentamento individual, você não encontra um pé de itauba e essas comunidades estão atravessando para a Resex para sobreviver, porque eles sobrevivem, eles não vivem, eles não têm mais o que vender, eles não tem mais uma madeira para ti fazer uma canoa. Essa briga de terras com o Governo do Pará dividiu, então esse problema aí nós estamos enfrentando [...]. Em Mariazinha, um assentamento individual, foram vendidos 10 mil hectares de terras para madeireiros por 900 mil reais, então essa luta vai continuar. Hoje a gente sente que um grande problema que nós da Resex vamos enfrentar é o deslocamento dessas famílias que estão em assentamentos criados pelo Estado do Pará para dentro da unidade de conservação a gente já começa a perceber esse problema, porque eles venderam, venderam não, eles deram o que era deles, barato, de graça para madeireiros para serem aprovados os projetos de manejo e hoje eles ficaram sem nada (Entrevista com liderança da Resex Tapajós-Arapiuns, Santarém/PA, 04/06/2012).

A atuação do Estado como motor do colonialismo interno (Gonzalez-Casanova, 2006) tem historicamente provocado um movimento, sobretudo na região Amazônica, que transforma os sem título e com posse em novos trabalhadores sem terra. ${ }^{4}$ A ocupação territorial se realiza em nome da propriedade privada da terra e da relevância econômica da propriedade fundiária como fonte da geração de recursos financeiros (Martins, 1998). 
Nesse contexto, a valorização mercantil das terras decorrente da expansão da acumulação capitalista acaba por influenciar a decisão dos ocupantes, sejam estes populações tradicionais ou camponesas, no que concerne à necessidade de se requerer a titulação cartorial. Se de um lado a regularização fundiária induzida pelas frentes de acumulação pode catapultar processos políticos que demandam do Estado o reconhecimento de territórios coletivos, por outro, representa a possibilidade de inserção de novas terras nos circuitos de valorização econômica. No tocante à inserção mercantil, Rosset (2004) argumenta que, da ótica do Banco Mundial, na ausência de um mercado imobiliário onde as pessoas possam comprar e vender terras, usá-las para assegurar empréstimo ou dar como garantia do aporte de recursos, não haverá investimentos na produção rural, tendo em vista que os investidores exigem a segurança do direito de propriedade. A despeito disso, como veremos na sessão seguinte, vêm ocorrendo processos de luta que demandam do Estado a titulação coletiva das terras, possibilitando estabelecer a inalienabilidade das mesmas através de mecanismos do programa de reforma agrária, uma estratégia diametralmente oposta à política tradicional, que tem ao longo dos anos privilegiado a constituição de assentamentos com demarcação de lotes individuais e potencial inserção no mercado imobiliário.

\section{A territorialização da luta por terra frente às dinâmicas de expansão do capital}

Embora essa visão mercantil de destinação de terras tenha se consolidado como hegemônica, uma série de movimentos sociais e organizações comunitárias vem se mobilizando na região amazônica no sentido de questionar esse modelo individualizado de constituição de assentamentos. As comunidades organizadas na esfera local e regional por intermédio de associações comunitárias, tais como a Acorjuve - Associação das Comunidades da Região de Juruti Velho e a Acoglec - Associação Comunitária da Gleba do Curumucuri, passam a demandar do Estado a regularização fundiária das terras por meio do reconhecimento de formas especificas de uso e apropriação dos recursos naturais, que por sua vez requerem sua retirada do mercado imobiliário pela via da regularização com titulação coletiva e cláusula de inalienabilidade. Isso pode ser constatado no trecho reproduzido a seguir, extraído de entrevista realizada com uma liderança comunitária de Juruti Velho/PA, que narra a cronologia da luta pelo estabelecimento de um assentamento 
de reforma agrária que possibilitasse manter a integridade do território ancestralmente ocupado pelas comunidades ribeirinhas:

Em 2004 não tínhamos pensado ainda na ideia do título coletivo, aí veio aqui um representante do Incra, Miranda, ele dizia que nós tínhamos que titular individualmente, cada comunitário ter seu documento, mas, como nós já vínhamos com a ideia do coletivo por causa da associação, isso não foi pra frente. Aí saiu o Miranda e assumiu outro superintendente chamado Pedro Peloso, aí nós propusemos para ele e para o Incra que nós queríamos o título coletivo, não conseguimos com o Pedro Peloso porque ele se aliou logo à Alcoa [mineradora presente na região]. Nós fomos chamados por ele lá para Santarém para que a Alcoa demarcasse nossas terras, só aí nós fomos descobrir que eles não queriam titular coletivamente por causa da Alcoa que estava chegando. Aí começou uma discussão entre nós e o Incra, nós dizendo que não, que nós queríamos coletivo, porque nós já tínhamos uma associação coletiva. Aí mexe vem, fomos para as comunidades dizer o que é um título coletivo, aí de novo deu outra discussão com os comunitários, porque naquele momento muitos queriam vender suas terras e um título coletivo impede toda venda, muitos diziam que nós queríamos titular essas terras para as irmãs [referência ao apoio de uma congregação da igreja católica] venderem para Alemanha, aí rolou muita discussão. Nessa época sai o Pedro Peloso e assume o Aquino, uma cara muito bom que assumiu o Incra, nós propusemos para ele o título coletivo e ele topou, ele escreveu logo lá nos autos que se o Incra tivesse que titular e criar um assentamento aqui na região de Juruti Velho teria de ser título coletivo, porque estava entrando uma mineradora, porque evitava a venda das terras. Aí começamos o debate, só que lá em cima em Brasília eles queriam individual por conta do projeto da Alcoa e nós aqui embaixo dizendo que nós queríamos outra modalidade. Conseguimos fechar essa ideia do coletivo com a companheirada, fizemos uma discussão com o Incra e aí o Aquino encaminhou todo esse processo de um título coletivo. A maior dificuldade era que não havia uma lei que amparasse esse título coletivo, tinha que ter um parecer de alguém. Nesse período, o Dr. Dilton estava no Incra e ele redigiu um parecer favorável à concessão do título coletivo, Brasília aprovou, mas mesmo assim a Alcoa continuava batendo, porque eles entenderam, a Alcoa entendeu mais rápido que nós o que era um título coletivo, porque o que eles tinham de proposta de comprar terra aí dentro de comunitário, não era brincadeira. Se o Incra tivesse titulado individualmente todas essas terras os comunitários teriam negociado com a empresa (Entrevista com liderança comunitária de Juruti Velho, Juruti/PA, 03/06/2012).

Esse fragmento exemplifica um processo mais amplo que tem se desenrolado no Oeste Paraense, principalmente em zonas de expansão das novas frentes de acumulação. Os movimentos sociais e organizações comunitárias têm pressionado os órgãos fundiários a constituírem assentamentos da reforma agrária que garantam a integridade do território por intermédio da titulação coletiva. Nesse sentido, pode-se sugerir a existência de um processo de territorialização da luta pela terra que, de um lado, procura conter a 
mercantilização e o avanço de um regime de propriedade privada que, não raro, facilita a concentração fundiária, e, de outro, sinaliza a possibilidade de constituição de um novo modelo de reforma agrária capaz de fortalecer e afiançar a permanência das populações tradicionais e comunidades camponesas em seus lugares de origem. A conduta territorial surge, portanto, quando as terras de um grupo estão sendo invadidas ou ameaçadas numa dinâmica em que, internamente, a defesa do território torna-se um elemento unificador do grupo e, externamente, as pressões exercidas por agentes do mercado ou pelo Estado, moldam ou impõem novas formas de organização (Little, 2002).

Como resultado da ameaça de expropriação representada pela presença de madeireiros, sojicultores e mineradoras, surge no interior das comunidades um processo de organização política que objetiva manter a continuidade de formas específicas de uso e apropriação dos recursos naturais que, ao mesmo tempo, pode ser visto como uma forma de resistências às novas dinâmicas de ocupação. Traços desse processo de territorialização das lutas podem ser inferidos dos trechos transcritos a seguir, que foram extraídos de entrevistas realizadas com uma liderança religiosa que apoia o embate das populações ribeirinhas e com um representante da associação comunitária do distrito de Juruti Velho/PA:

A estratégia tem sido assim, tem pessoas que elas dizem assim: eu tenho medo de não garantir que eu continue aqui, nesse meu pedacinho de chão, eles dizem assim, aí nós dizemos assim: então vamos juntar o seu medo com o medo de mais alguns e vamos transformar esse medo em coragem, o que é coragem? É a coragem de juntos nós lutarmos para que o território todo seja garantido. Foi essa a discussão que fizemos na gleba Curumucuri, que é uma extensão bastante considerável, num determinado momento eu sentei com os padres lá em Juruti e fiz uma reflexão com eles, eu estava sentindo que o governo do Pará através do Iterpa tinha receio de garantir o território para os moradores da gleba Curumucuri. Eu disse assim, olha, se nós não formos aos comunitários e refletirmos com eles e sentirmos quais são as dificuldades deles e refletirmos com eles sobre a importância do coletivo, porque é isso que eles tem feito ao longo da vida deles, eles fazem muita roça coletiva, o trabalho religioso seja evangélico, seja católico é coletivo, as melhorias que eles fazem na escola é coletiva, eles limpam ramais é coletivamente, a vida deles tem se expressado em uma coletividade. Eu disse assim, ou a gente garante isso através de nosso apoio, de nossa fala, de dizer para eles que eles não estão sozinhos, nós estamos nessa luta com vocês ou o Estado vai chegar aqui e vai dizer: eu vou dar três hectares para o senhor, vou dar dez para você e vai repartir esse território e as pessoas vão ficar mais fragilizadas ainda. [...] Para mim é assim a fragilidade se dá se você começa a dividir em porções de terra e você tira essa compreensão de território (Entrevista com liderança religiosa B. Óbidos/PA, 05/06/2012). 
Aqui nós brigamos para que o nosso território seja coletivo, porque entre nós trabalhadores, mesmo quem mora, por exemplo, na gleba Mamurú-Rio, na gleba Curumucuri, na gleba Juruti Velho, na gleba Nova Olinda III, não tem separação entre nós, não tem cerca entre as nossas limitações. Por exemplo, a gleba Curumucuri junta castanha dentro da gleba Juruti Velho; Juruti Velho junta castanha dentro da gleba Nova Olinda III, porque está tudo interligado, então para nós não tem limitações entre os tradicionais, porque uma gleba, um comunitários de tal gleba precisa da outra, então eu acho que essa é a diferença entre defender a terra e o território que a gente tem realizado aqui na Amazônia (Entrevista com liderança comunitária de Juruti Velho, Juruti/PA, 03/06/2012).

A territorialização da luta com o objetivo de permanência no lugar se dá, portanto, não apenas através das tradicionais estruturas intermediárias do grupo étnico, dos grupos de parentes, da família, do povoado, mas também por um certo grau de coesão e solidariedade obtido em face de antagonismos e situações de extrema adversidade e de conflito que reforçam as redes de relações sociais (Almeida, 2004). As pressões e conflitos aparecem, assim, como catalisadores da mobilização política, onde a conflitividade se torna um elemento chave no engendramento de processos emancipatórios através dos quais a contradição é usada positivamente como uma arte que politiza a diferença (Rancière, 2007). $\mathrm{Na}$ tentativa de dar significado a essas novas formas de organização política, Almeida (2004) sugere o uso do conceito de unidades de mobilização, que se refere à aglutinação de interesses específicos de grupos sociais não necessariamente homogêneos, que são aproximados circunstancialmente pelo poder nivelador da intervenção do Estado ou pelo avanço de formas capitalista de ocupação. No interior desse movimento há, portanto, mais que uma estratégia discursiva; tem-se o advento de categorias que se afirmam através de uma existência coletiva, politizando não só as nomeações da vida cotidiana, mas também certo modo de viver que abrange suas práticas rotineiras de uso dos recursos naturais (Almeida, 2008). Para Leroy (2010), em todos os lugares da Amazônia brasileira, grupos sociais começaram, a partir dos anos 1990, em razão do avanço das frentes de acumulação capitalista, a buscar formas de mobilização política e jurídica através das quais pudessem se enquadrar para afirmarem e manterem suas territorialidades numa constante negociação entre as territorialidades expressas pelo Estado e aquelas vivenciadas pelos povos e comunidades tradicionais.

Pode-se conjecturar que a mobilização que requer a posse legal das terras decorre, assim, da ameaça representada pela expansão das frentes de acumulação capitalista expressas na atuação de mineradoras, sojicultores, pecuaristas e madeireiros. Martins (1996) 
afirmava, àquela época, que um posseiro da Amazônia justificava seu direito à terra invocando o direito que teria sido gerado como fruto do seu trabalho na terra. Não obstante, pode-se dizer que hoje se aglutinam outras formas de justificação, que vão desde o recurso a dispositivos jurídicos que afiançam a ocupação tradicional, passando pela pertença simbólica de grupos étnicos e aportando no discurso de preservação ambiental. $\mathrm{Na}$ ausência de pressões resultantes do avanço da acumulação capitalista, a relação absolutamente específica que o membro de uma comunidade ribeirinha, quilombola ou indígena estabelece com o território permite-lhe pensar não ser necessário documentar a relação com a terra, uma vez que desde sua mirada todo o direito sobre a terra se fundamenta na continuidade de um modo específico de uso e apropriação dos recursos naturais (Araújo, 2010). Entretanto, os conflitos desencadeados pela chegada de formas de ocupação mercantil acabam por alterar essa dinâmica, forçando a busca pela regularização fundiária, quer seja por via da demanda por reconhecimento de territórios étnicos, quer pelos instrumentos da reforma agrária. Sobre esse aspecto, os trechos reproduzidos a seguir, extraídos de entrevistas realizadas com representante do Instituto de Terras do Pará - Iterpa e com liderança da Terra Indígena Maró, ilustram os efeitos da chegada de novas frentes de acumulação sobre as formas de organização social e de organização das demandas por regularização fundiária:

Determinadas comunidades quilombolas elas estavam até então, como eu falei anteriormente, com a terra pacificada e vivendo uma convivência harmoniosa lá, sem problema nenhum, a partir desse momento [chegada de madeireiros, sojicultores e mineradoras] elas foram procurar seus direitos porque estavam se sentindo usurpadas dos seus territórios e ameaçadas também. Com isso foram procurar seus direitos e muitas passaram a descobrir os novos mecanismos do governo, do poder público em reconhecer as comunidades tradicionais, todo um processo amparado na própria constituição. Com toda essa chegada dessas frentes ocorreu essa consciência de muita gente que tava parada e passou a ir ao Iterpa, que tinha uma demanda bem pequena de comunidades requerendo seu reconhecimento, isso aumentou significativamente, porque passaram outras comunidades a nos procurar e a dar entrada nos seus pedidos e requererem os seus reconhecimentos (Entrevista com membro do corpo técnico do Iterpa, Belém/PA, 23/05/2012).

$\mathrm{Na}$ verdade, nós enfrentamos muitos conflitos desde o início quando nós começamos a travar essa luta para demarcação da terra indígena Maró. Antigamente não havia essa necessidade até porque nós vivíamos lá quase isolados, não tinha perseguições, nós podíamos caçar e viver somente da caça e da pesca [...]. O Estado do Pará quando foi criada a terra indígena Kaiapó como não tinha como indenizar os madeireiros que estavam lá e tinham comprado terras, o Estado jogou eles lá pra gleba Nova Olinda, onde é a terra 
indígena Maró. O Estado dizia que lá era terra devoluta e que não havia ninguém lá morando, então esse pessoal chegou lá, não conversaram com a gente e começaram a extração de madeira, então a partir daí nós começamos a travar nossa luta para a demarcação porque havia uma necessidade de garantir o nosso território, que a gente pudesse preservar a tradição, a cultura, para não se perder, porque nós tínhamos noção de como tinha acontecido já em outras áreas (Entrevista com liderança da Terra Indígena Maró, Santarém/PA, 09/06/2012).

$\mathrm{Na}$ ótica dos representantes do complexo agro-mineiro eletrointensivo, povos indígenas, populações camponesas, quilombolas e comunidades tradicionais são comumente vistos como obstáculos à instalação de novos empreendimentos e como entraves às transações do mercado de terras, uma vez que suas formas de uso e apropriação dos recursos naturais são regidas por uma lógica que tem o potencial de constranger o avanço da exploração capitalista. $\mathrm{Na}$ esteira das lutas por reconhecimento, travadas por indígenas, quilombolas e populações tradicionais, pode-se indicar que a territorialização das lutas por reforma agrária, que vem sendo empreendida por comunidades ribeirinhas do Oeste do Pará, cuja peculiaridade é a apresentação de demandas por titulação coletiva dos assentamentos, representa um novo modelo com consequências importantes sobre a reconfiguração da propriedade fundiária no país. A despeito de o sistema de uso comum sempre ter sido marginalizado na estrutura agrária brasileira, a ponto de não haver um conceito de áreas de uso comum juridicamente consolidado (Benatti, 1999), as comunidades ribeirinhas têm se mobilizado para demandar dos órgãos fundiários a constituição de assentamentos que mantenham a integridade da ocupação. Assim sendo, os trechos transcritos a seguir, que compõem entrevistas realizadas com um líder comunitário de Juruti/PA e um representante da Comissão Pastoral da Terra de Óbidos/PA, podem ilustrar as vicissitudes desse processo e seu potencial no que tange à manutenção dos modos de vida praticados pelas comunidades ribeirinhas, quer essas se autorreconheçam ou não como populações tradicionais:

A titulação coletiva tem essa força porque os comunitários entendem isso, por exemplo, as leis e as regras que são colocadas nos papéis com relação à titulação coletiva eles sustentam mais. As leis que estão hoje fincadas na CDRU [Concessão de Direito Real de Uso] ${ }^{5}$, elas sustentam mais o povo tradicional na terra, então tem uma segurança muito grande do título coletivo para o povo tradicional de uma região. O que falta é o Incra encampar isso como modelo de titulação para todos os assentamentos. O nosso é o único na Amazônia e no Brasil, eu não conheço se tem outro em outra região, mas eu acho que se o Incra encampar isso como modelo de segurança para quem está em cima da terra, de dizer para o comunitário que não pode vender e colocar essa regra no 
documento, com certeza os assentamentos na Amazônia e no Brasil serão diferenciados de todos aqueles que são individuais. Porque hoje se você for num assentamento individual, por exemplo, num PA, como a gente tem aqui, $50 \%$ das famílias não é mais tradicional, nós temos o PA Socó aqui, se você for lá $50 \%$ das pessoas que estão lá hoje não são mais tradicionais, são pessoas que chegaram de Manaus, de Óbidos que compraram e se apossaram das terras [...]. Com essa titulação coletiva, se o Incra puxar para si e disser que essa é a melhor modalidade e fazer normas, a realidade pode mesmo mudar (Entrevista com liderança comunitária de Juruti Velho/PA, 03/06/2012).

Eu vejo assim uma diferença, não vou dizer que todos os moradores passam a ter essa compreensão, assim, vamos defender porque é nosso, é o nosso território, mas as pessoas passam a si dar conta que essa defesa do coletivo, essa defesa do território é capaz de garantir esse modo de viver, de morar na vila, de ter uma área de várzea, de ter uma área de terra firme. Quando a gente conversa com eles e diz assim; se você abrir mão do coletivo você vai ter que fazer a opção; ou ficar na várzea ou ficar na terra firme. É aí que a pessoa vai dizer assim: então se eu optar pelo coletivo eu estarei garantindo essa minha maneira de viver? Tá. Se for pelo individual a senhora ou senhor vai ter que fazer uma escolha, a senhora ou o senhor consegue fazer essa escolha? Não. Mas olha, nesse momento as pessoas começam dar as razões para ter a terra firme e as motivações para ter a terra de várzea, por isso que eu digo assim, você não consegue desvincular o amazônida da terra e da água. Homem, terra e água estão interligados aqui na Amazônia, então aqui não se consegue pensar o homem fora dessa lógica do território (Entrevista com liderança religiosa da CPT, Óbidos/PA, 05/06/2012).

A constituição de assentamentos da reforma agrária com titulação coletiva das terras tem potencial de minar o caráter mercantil da terra e imobilizar as transações comerciais, ao mesmo tempo em que restringe a atuação dos mecanismos que facilitam a concentração fundiária e garante a integridade da ocupação. Esse processo de territorialização das lutas por terra em curso no Oeste do Pará se assemelharia, portanto, ao que Mauro Almeida (2007) identifica como sendo uma nova reforma agrária, por assim dizer, transfigurada em uma pluralidade de movimentos e questões, que traz novos recortes da luta pela redistribuição do espaço natural. Da mesma forma, guarda paralelo com o que Mannathukkaren (2011) descreve ao analisar a reforma agrária em Kerala, na Índia dos anos 1960, onde os enfrentamentos para obtenção de terras não eram apenas uma luta material, mas, também e simultaneamente, um embate simbólico contra a opressão e pelo direito ao exercício de formas diferenciadas de se viver. Não obstante, há que se considerar que esse processo de territorialização das lutas por reforma agrária é, a rigor, um fenômeno próprio de regiões de fronteira, onde as populações ainda não foram expropriadas e detêm, não raro por via da resistência, sua permanência na posse da terra. 
Como exemplo da diferenciação entre os movimentos que lutam para manter a posse da terra/território e aqueles que lutam para reconquistar o direito a terra já expropriada, podem-se citar os fragmentos a seguir, que foram retirados de entrevistas realizadas com uma liderança comunitária de Juruti Velho/PA e com dirigente da Coordenação das Associações das Comunidades Remanescentes de Quilombos do Pará;

A gente tem uma diferença porque aqui na Amazônia nós lutamos para garantir a permanência na terra, os movimentos de fora, tipo Via Campesina, MST e MAB, eles lutam para conquistar o que eles perderam, essa diferença é muito grande. Aqui nós estamos lutando para manter o que temos e essa companheirada aí fora luta para reconquistar o que já foi tomado, então essa diferença é muito grande entre nós os trabalhadores da Amazônia e outros trabalhadores fora da Amazônia (Entrevista com liderança comunitária de Juruti Velho/PA, 03/06/2012).

O direito aos territórios, eu costumo dizer, é um contraponto à reforma agrária tradicional, nós não vemos a terra como uma mercadoria, para nós é um terreno sagrado. A reforma agrária é uma titulação individual e na pressão dos que chegam de fora com o dinheiro muitos acabam cedendo à compra. No nosso caso, a titulação é coletiva e isso nos dá mais uma garantia. Tem outra diferença importante: o MST, por exemplo, está na luta e na procura de uma terra para se assentar e nós já estamos no nosso território há centenas de anos e na minha avaliação isso nos diferencia. (Entrevista com liderança quilombolas, Belém, 28/05/2012).

Para Alfredo Wagner de Almeida (2011), a demarcação de territórios e o reconhecimento de identidades tradicionais são uma forma de resistência mais eficaz e imediata às agroestratégias em comparação às outras modalidades de luta e reivindicação fundiária. No entanto, a partir do processo de territorialização das lutas por terra em curso no Oeste do Pará, é factível indicar que a constituição de assentamentos da reforma agrária com titulação coletiva e cláusula de inalienabilidade pode de igual maneira minimizar os impactos das frentes de acumulação. Por essa via, um morador do meio rural que não possui do ponto de vista legal nenhuma particularidade, especificidade ou atributo diferencial que o associe à qualificação de população tradicional e que tampouco se autorreconheça como tal, pode ainda assim acionar sentidos afetivos que o atam a uma terra específica, que remetem à história e a memória coletiva do grupo, que dão à ocupação da terra significações de pertencimento que lhe possibilitam insurgir-se na defesa de seu lugar específico.

Esse processo de titulação coletiva de terras via mecanismos da reforma agrária lança luz sobre o uso de categorias dicotômicas que associam o território às ideias de 
coletividade, uso comum, significação simbólica, estar fora do mercado e reprodução social, características interligadas, por sua vez, às formas prático-teóricas de se pensar as populações tradicionais, enquanto que a luta por terra é enxergada segundo as noções de individualidade, propriedade privada, transação de mercado e produção econômica, que sugerem os atributos "diferenciais" através dos quais as populações camponesas vêm sendo pensadas. Pode-se sugerir, portanto, que o enfrentamento levado a cabo pelo camponês não está desvinculado dos aspectos culturais de pertencimento ao seu lugar de origem, do mesmo modo que a luta das populações tradicionais não se dá no vácuo de influência dos circuitos econômico-instrumentais. Assim, na luta das comunidades tradicionais, têm se privilegiado, intelectual e politicamente, certos aspectos e traços que, podendo já estar presentes naqueles grupos que no passado ou em outras circunstâncias se identifica(ra)m como "camponeses", não foram nesse último caso objeto de maiores investimentos por parte de intelectuais e movimentos sociais (Guedes, 2011). ${ }^{6}$ Como sugere Mauro Almeida (2007), a construção de culturas camponesas dotadas de peculiaridades linguísticas, religiosas, tecnológicas e sociais, que vão de modos de falar a regras de propriedade, pode funcionar como arma política para reivindicação de direitos fundiários, jurídicos e educacionais.

Embora os movimentos sociais e organizações comunitárias venham pressionando os órgãos fundiários da esfera federal e estadual para consolidação de assentamentos com titulação coletiva e cláusula de inalienabilidade por via da Concessão de Direito Real de Uso, já são visíveis as estratégias utilizadas pelo Estado para corroer a força diferencial desse tipo de regularização e destinação das terras. Isso pode ser percebido no trecho disposto a seguir, que compõe entrevista realizada com um membro do corpo técnico do Instituto de Terras do Pará - Iterpa:

Algumas comunidades até, vamos dizer assim, orientadas pelos movimentos e pelos sindicatos de trabalhadores rurais, orientando-os ao procedimento de que a regularização fosse assim aos moldes do reconhecimento quilombola, coletiva, ou seja, que a comunidade requeresse o território coletivo, mas isso vai muito de encontro com a questão da posse, é diferente da questão quilombola, porque a questão quilombola não é uma regularização é um reconhecimento de uma situação de propriedade já existente, já é consagrada. Nas comunidades que não são quilombolas é diferente são pessoas com direito de posse ocupando uma determinada região [...]. O governo anterior dentro dessa filosofia de atender essas demandas ele criou o chamado assentamento coletivo, que é o projeto de assentamento agroextrativista, que é coletivo [...]. Mas hoje essas comunidades não quilombolas já abdicaram, como a colega falou anteriormente aqui, elas estão requerendo sua regularização individual, 
por quê? Porque elas viram a dificuldade do instrumento e a falta de recurso [...] então na questão aqui do Estado elas não teriam, teriam a dificuldade desses instrumentos, então elas estão optando pelo o quê? Não! Eu quero meu título, minha regularização individual. Então é isso que tem ocorrido, muita coisa tem sido desfeita na questão dos assentamentos para serem feitas as regularizações individuais (Entrevista com Y representante do corpo técnico do Iterpa, Belém, 23/05/2012).

A morosidade dos órgãos fundiários e a ausência de mecanismos de suporte à permanência das famílias têm ocasionado a reversão dos processos de constituição de assentamentos com titulação coletiva. Isso guarda similaridade com os argumentos de Bromley (1989), quando este sugere que a história do desenvolvimento em países periféricos tem tido como foco quase exclusivo a promoção da propriedade privada da terra, quer sob a forma de práticas agrícolas altamente tecnificadas ou pela condução de programas de reforma agrária que estimulam a mercantilização e privatização das terras. Nessa linha de conduta, pouco ou nenhum esforço é direcionado para compreensão e estímulo de atividades econômicas que se baseiam em outros regimes de uso e apropriação das terras. Apesar da pressão exercida pelos movimentos sociais e organizações comunitárias no que concerne à implantação de assentamentos com titulação coletiva, o Estado, tanto na esfera federal por intermédio do Incra, como no âmbito estadual por meio do Iterpa, tem dado demonstrações de uma reorientação na política de destinação de terras. Traços dessas diretrizes podem ser depreendidos do fragmento disposto a seguir, que foi retirado de entrevista realizada com assessor jurídico das comunidades ribeirinhas:

Hoje corre o risco das populações que moram nessas áreas serem expulsas, porque enquanto o Incra fica na letargia de não resolver esse problema [expedir a titulação coletiva], os madeireiros ilegais, os sojeiros e os mineradores, eles entram nessas áreas, agora mesmo pela manhã eu recebi uma ligação de uma liderança lá de Alenquer, dizendo: olha nós estamos vivendo numa situação muito difícil, pessoas que têm áreas dentro do assentamento ou nas proximidades estão procurando os trabalhadores para tentar convencê-los a desistir do projeto de assentamento e isso vai ser muito ruim para o trabalhador, porque o assentamento coletivo é uma forma também de unidade. Os grandes proprietários chegam dizendo: o Incra não vai resolver o seu problema, desde 2007 que criou o assentamento e até agora não resolveu, portanto é melhor tu sair do assentamento coletivo, pede sua desistência e faz um pleito particular. É a lógica do individualismo, tudo isso é um risco, mas a lógica dos trabalhadores rurais tradicionais da Amazônia é uma lógica coletivista, é intrínseco deles (Entrevista com assessor jurídico da associação de moradores de Juruti Velho, Santarém, 10/06/2012). 
Na visão de Alfredo Wagner Almeida (2008), a despeito das mobilizações sociais e de suas repercussões na vida cotidiana das comunidades, não têm diminuído, contudo, os entraves políticos e os impasses burocrático-administrativos que procrastinam a efetivação do reconhecimento jurídico-formal das terras tradicionalmente ocupadas. Como estratégia de desarticulação das comunidades pode-se indicar a política estatal de regularização fundiária pela modalidade de titulação individual, que facilita a inserção de novas terras no mercado por via da consolidação de assentamentos da reforma agrária. Assim, as comunidades que detêm a posse das terras localizadas em zonas de expansão de novas frentes de acumulação são incitadas a promover a regularização fundiária pela via da titulação individual, que por sua vez possibilita as transações de compra e venda das propriedades, impulsiona a concentração de terras, fomenta o mercado de empréstimos bancários cuja garantia é a terra, bem como facilita a privatização de terras públicas ou de uso comum. Nesse quesito, vale destacar o trecho transcrito a seguir, que foi extraído de entrevistas realizadas com técnicos do Iterpa e deixa transparecer as relações de proximidade, não raro de parceria, entre o órgão fundiário e o avanço territorial de novas frentes de exploração mercantil:

As grandes empresas estão chegando aos municípios e procuram o órgão [Iterpa] porque precisam da situação fundiária, tá? Então precisam saber aquela situação fundiária. Eles, [grandes empresas], via de regra, fazem um levantamento das comunidades e as pessoas, às vezes em determinadas regiões num percentual muito grande, dizem: não tenho o documento da terra ainda, tenho só minha posse. Como a transação é feita com recurso de investimento bancário, o banco exige o documento da terra. Aí eles vêm ao órgão e aí começa uma conversação no sentido de que o órgão desenvolva uma campanha naquele local visando dar o título para cada uma daquelas parcelas que estão ocupadas e exploradas, com isso aí eles têm como desenvolver o projeto para o plantio de dendê (Entrevista com Y representante do corpo técnico do Iterpa, Belém, 23/05/2012).

Essa regularização fundiária por meio da titulação individual pode ser vista como uma forma de dinamização do mercado de terras que possibilita inserção de novos espaços nos circuitos de acumulação do capital, ao mesmo tempo em que facilita a tarefa imprescindível de progressivamente dispor de maior quantidade de terras para poder fazer uma seleção quantitativa e qualitativamente ilimitada dos meios de produção (Luxemburgo, 1970). O modus operandi narrado pelo técnico do Iterpa se assemelha, por sua vez, ao que prescreve a política fundiária do Banco Mundial no que tange à regularização de terras, na qual se encontra uma sugestão de medidas a serem implantadas pelos governos que perpassam o cadastro, registro e demarcação das terras, privatização de terras públicas e comunais, 
concessão de títulos alienáveis, estímulo ao mercado de terras e fomento ao crédito para os beneficiários dos programas agrários (Rosset, 2004).

Ao despender esforços e recursos na privatização de terras públicas por intermédio da consolidação de assentamentos com titulação individual, que usualmente contrariam as demandas das populações ribeirinhas, o Estado perpetua um cenário de exploração e exclusão. No entanto, o faz legitimando-se pelo discurso de incremento da destinação de terras, que faz crer na eficiência da gestão territorial, mas obscurece o fato de que a titulação individual, não raro, insere novos espaços no mercado. Sem o apoio das políticas públicas de fomento à produção, na ausência de crédito para fortalecer a atividade extrativista, no vácuo de investimento em infraestrutura de escoamento dos produtos e deslocamento das pessoas, na inexistência de eletrificação rural e sem acesso à equipamentos básicos de saúde e educação, as populações acabam sucumbindo ao assédio de madeireiros, grileiros e fazendeiros, que tanto recorrem ao expediente da compra de terras de comunidades assentadas como expulsam aquelas que secularmente mantêm a posse da terra sem, no entanto, possuir um título de propriedade. Ainda que possuam o título de propriedade, esse fator não tem garantido a permanência das populações em suas terras, mas, ao contrário disso, vem funcionando como indutor da inserção de terras públicas nos circuitos do mercado.

\footnotetext{
${ }^{1}$ O conjunto de glebas Mamurú-Arapiuns se localiza na porção oeste do estado do Pará e se espraia pelos municípios de Aveiro, Santarém e Juruti, fazendo fronteira ao norte com o rio Amazonas, ao sul com o Parque Nacional da Amazônia e com a Terra Indígena Andirá-Marau, a leste com a Reserva Extrativista Tapajós-Arapiuns e a oeste com o Estado do Amazonas (Iterpa, 2009). As terras que compõem o conjunto de glebas Mamurú-Arapiuns foram matriculadas e arrecadadas em nome do Estado do Pará e perfazem um total de 1 milhão e 312 mil hectares de florestas contínuas, que são de grande importância no que se refere à preservação ambiental e à reprodução social de comunidades tradicionais. Ademais, essa região possui um enorme potencial para extração de recursos naturais, sobretudo nos segmentos da exploração madeireira e mineral (Assis, 2010). Por ser uma porção territorial muito distante das sedes municipais e ter o acesso dificultado pela quase inexistência de vias terrestres, sendo os rios a principal forma de interligação, tem se verificado uma ausência do poder público na fiscalização da ocupação ilegal de sojicultores e madeireiros.

2 Ao hospedar-me em Santarém, a recepcionista do hotel fez uma cara de surpresa quando, ao me indagar a profissão, respondi que era sociólogo. Ao perguntá-la sobre a razão do espanto, ela completou dizendo: "Aqui sempre chegam engenheiros ou geólogos, sua profissão é bem diferente, fico imaginando o que será que vem fazer um sociólogo aqui em Santarém?" Comentei em tom de brincadeira que vinha ver o que os outros estavam fazendo e ela respondeu: "Se é isso, o senhor vai ver muitos problemas por aqui".

${ }^{3}$ Palmeira (1989), analisando as mudanças institucionais ocorridas no cenário nacional nas décadas de 1960 e 1970, afirma que as vantagens asseguradas pelo Estado no bojo da política de modernização do campo atraíram para atividades agropecuárias e agroindustriais, mas sobretudo para a especulação fundiária, capitais
} 
das mais diversas origens, criando uma coalizão de interesses em torno do negócio com a terra incrustada na própria máquina de Estado.

${ }^{4}$ Moacir Palmeira (1989) já assinalava que se no passado o trabalhador expulso encontrava casa e trabalho em condições semelhantes numa outra propriedade, ou mesmo num momento seguinte reconstituía sua condição de posseiro, mas na expulsão recente a saída é definitiva. Essa constatação guarda relação de complementaridade com o trecho reproduzido a seguir, que foi extraído de entrevista realizada com uma liderança sindical do município de Santarém/PA: "O agricultor familiar já foi considerado aqui como amansador de terra, simplesmente amansador de terra, vai lá derruba a floresta, vira capoeirinha, depois eles diz, não, não dá, tenho que procurar outra floresta para eu derrubar, porque essa aqui não dá mais, não produz. Vai passando em frente, aí chega uma pessoa com um pouco de tecnologia e torna aquela terra muito produtiva, e ele derruba aqui, derruba ali, mas com essa criação de assentamentos e com a ocupação pela soja, isso de certa forma, fica mais difícil de fazer, até porque também não tem mais terra, para você chegar lá e de qualquer jeito ocupar, quer dizer as terras da união hoje estão quase todas ocupadas, então não tem mais para onde correr" (Entrevista com liderança sindical, Santarém, 12/06/2012).

${ }^{5}$ A previsão legal do contrato de Concessão de Direito Real de Uso está no decreto lei 271 de 28 de fevereiro de 1967, o qual estabelece que a CDRU de terreno seja o contrato solene, pelo qual se transfere, a título de direito real, o usufruto temporário, por prazo certo ou indeterminado, de terreno público para fins específicos de urbanização, industrialização, edificação, cultivo da terra ou outra utilização de interesse público (Benatti, 1999).

${ }^{6}$ Oliveira (2010) destaca que os conflitos e lutas por terra envolveram no Brasil mais de 17,7 mil famílias de posseiros no último ano, enquanto que os sem-terra mobilizaram cerca de 14,9 mil. Esse protagonismo dos posseiros demonstra que a luta camponesa extrapola a influência e mobilização dos movimentos socioterritoriais institucionalizados e organizados nacionalmente.

\title{
Referências bibliográficas
}

\author{
ACSELRAD, Henri
}

2012 “Apresentação”. In ACSELRAD, Henri (org.). Cartografia Social, Terra e Território.

Rio de Janeiro, Ippur/UFRJ.

AlmeidA, Alfredo Wagner Berno de

2011 “A reconfiguração das agroestratégias: novo capítulo da guerra ecológica”. In Sauer, Sérgio e AlmeidA, Wellington. Terras e Territórios na Amazônia: Demandas, Desafios e Perspectivas. Brasília, Editora Universidade de Brasília.

2008 Terra de quilombo, terras indigenas, "babaçuis livre", "castanbais do povo", faixinais e fundos de pasto: terras tradicionalmente ocupadas. Manaus, Pgsca-UFAM.

1988 "Terras de preto, terras de santo e terras de índio: posse comunal e conflito". Revista Humanidades, n. 15: 42-48.

2004 “Terras tradicionalmente ocupadas: processos de territorialização e movimentos sociais". Revista Brasileira de Estudos Urbanos e Regionais, v. 6, n. 1: 9-32. 
Almeida, Mauro

2007 "Narrativas agrárias e a morte do campesinato". Ruris, v.1, n.2.

Araújo, Marlon Aurélio Tapajós

2010 "Reconhecimento dos Territórios Tradicionais por meio de políticas de ordenamento fundiário e a ambientalização das lutas das comunidades tradicionais de Juruti Velho, Juruti, Pará”. V Encontro Nacional da Anppas, Florianópolis.

Assis, W. F. T.

2010 “Conflitos Territoriais e Disputas Cartográficas: Tramas sociopolíticas no ordenamento territorial do Oeste do Pará”. In ACSELRAD, Henri (org.). Cartografia Social e Dinâmicas Territoriais: Marcos para o debate. Rio de Janeiro, Ippur/UrRJ, v. 2, pp. 163-193.

BenatTI, José Heder

1999 “A criação de unidades de conservação em áreas de apossamento de populações tradicionais". Novos Cadernos do NAEA, vol. 1, n. 2, Universidade Federal do Pará - Núcleo de Altos Estudos da Amazônia, Belém.

2011 "Propriedade comum na Amazônia: acesso e uso dos recursos naturais pelas populações tradicionais". In SAUER, Sergio et al. (org.). Terras e territórios na Amazônia: demandas, desafios e perspectivas. Brasília, Editora Universidade de Brasília.

BRITO, B. e BARRETO, P.

2011 A regularização fundiária avançou na Amaz̧ônia? Os dois anos do programa Terra Legal. Belém, Imazon.

BROMLEY, D.W.

1989 "Property relations and economic development: the other land reform". World Development, 17 (6): 867-877.

Gonzalez Casanova, Pablo

2006 "Colonialismo Interno: uma redefinição". In BORON, Atílio et al. (org.). La teoría marxista hoy: problemas y perspectivas. Buenos Aires, Clacso.

GuEDES, André D.

2011 “A Fronteira e as fronteiras entre camponeses, indígenas e comunidades tradicionais: relendo José de Souza Martins". Anais da XVII Semana PUR, XVII Semana PUR.

I 
TERPA - Instituto de Terras do Pará

2009 "Regularização Fundiária da região Mamurú-Arapiuns”. Seminário Ideflor: O potencial florestal dos novos marcos de gestão Púbica, comunitária e privada no Oeste Paraense. Santarém, Ideflor.

IANNI, Octavio

1979a. Colonização e contra-reforma agrária na Amazônia. Petrópolis, Vozes.

1979b A luta pela terra: historia social da terra e da luta pela terra numa área da Amazônia. Petrópolis, Vozes.

LEROY, Jean-Pierre

2010 “Amazônia: território do capital e territórios dos povos”. In ZHOURI, Andréa e LASCHEFSKI, Klemens (orgs.). Desenvolvimento e conflitos ambientais. Belo Horizonte, Editora UFMG.

LITTLE, Paul E.

2001 Amazonia: territorial struggles on perennial frontiers. Baltimore, Johns Hopkins University Press.

2002 "Territórios sociais e povos tradicionais no Brasil: por uma antropologia da territorialidade”. Série Antropologia, n. 322, 32p.

Luxemburgo, Rosa

1970 A acumulação do capital: estudo sobre a interpretação econômica do Imperialismo. Rio de Janeiro, Zahar.

MANNATHUKKaren, Nissim

2011 "Redistribution and recognition: land reforms in Kerala and the limits of culturalism". The Journal of Peasant Studies, v. 38, n. 2: 379-411.

MARTins, Jose de Souza

1981 Os camponeses e a política no Brasil: as lutas sociais no campo e seu lugar no processo político. Petrópolis, Vozes.

1979 O cativeiro da terra. São Paulo, Ciências Humanas.

1980 Expropriação e violência: a questão política no campo. São Paulo, Hucitec.

1998 “A Vida Privada nas Áreas de Expansão da Sociedade Brasileira”. In NovAES, Fernando (org.). História da Vida Privada no Brasil - Contrastes da Intimidade Contemporânea, vol. 4. São Paulo, Companhia das Letras.

1986 Não há terra para plantar neste verão: (o cerco das terras indígenas e das terras de trabalho no renascimento político do campo). Petrópolis, RJ, Vozes. 
1996 “O tempo da fronteira, retorno à controvérsia sobre o tempo histórico da frente de expansão e da frente pioneira". Tempo Social, vol., n.08: 25-70.

OFFEN, Karl

2009 "Ou mapeias ou te mapeiam: Mapeio indígena y negro en America Latina". Tabula Rasa, vol., n.10: 163-190.

Oliveira, Ariovaldo Umbelino de 2010 “A Questão da aquisição de terras por estrangeiros no Brasil - um retorno aos dossiês". Agrária, São Paulo, n. 12: 3-113.

PALMEIRA, Moacir

1989 “Modernização, Estado e questão agrária”. Estudos Avançados, 3 (7): 87-108.

Prado Junior, Caio

1971 História Econômica do Brasil. São Paulo, Brasiliense.

1979 A questão agrária no Brasil. São Paulo, Brasiliense.

RANCIÈRE, Jacques

2007 En los bordes de lo politico. Buenos Aires, La Cebra.

Rosset, Peter

2004 “O bom, o mal e o Feio: a política fundiária do Banco Mundial”. In O Banco Mundial e a Terra: ofensiva e resistência na América Latina, África e Ásia. São Paulo, Viramundo, pp.16-24.

SilVA, Jose Graziano da

1981 A modernização dolorosa: estrutura agrária, fronteira agrícola e trabalhadores rurais no Brasil. Rio de Janeiro, Zahar.

TURNER, Frederick Jackson e SIMONSON, Harold

1963 The significance of the frontier in American history. New York, Ungar.

VELHO, Gilberto

1981 Frentes de expansão e estrutura agrária. Estudo do processo de penetração numa área da Transamazônica. Rio de Janeiro, Zahar Editores.

WALLERSTEIN, Immanuel Maurice

1974 The modern world-system: capitalist agriculture and the origins of the European worldeconomy in the sixteenth century. New York, Academic Press.

WEBER, Max

1999 Economia e Sociedade: fundamentos da sociologia compreensiva. Brasília, Editora Universidade de Brasília. 


\title{
In the beginning was the Land: The territorialization of agrarian struggles in the context of the expansion of capitalist accumulation in the Amazon
}

\begin{abstract}
The paper analyzes complementarities and dissonances among peasant struggles for land, most often associated with land reform and redistribution mechanisms, and the conflicts carried out by indians, quilombolas and traditional populations that struggle for maintaining and conquering territories and at the same time require that the state recognize their specific ways of being, living and producing. To do so, fieldwork was undertaken in the western region of Pará, which over the last decade has been the locus of intense land conflicts involving new areas of capitalist accumulation and the traditional and peasant populations. It could be preliminarily suggested that a demand for land does not necessarily challenge the regulations of the right to property, whereas a territorial claim evokes issues of power, identity affirmation, selfmanagement and control of natural resources that seek to establish a new territorialization.
\end{abstract}

KEYWORDS: Land Conflicts, Territorial Struggles, Amazon.

Recebido em janeiro de 2014. Aceito em março de 2015. 